\title{
Graciela Sacco Una bocanada en el feminismo en disputa
}

\author{
Graciela Sacco \\ One Puff in the Feminism in Dispute
}

\section{Ludmila Polcowñuk \\ lupolco@hotmail.com}

Facultad de Artes. Universidad Nacional de La Plata. Argentina

Recibido: 29/9/2019

Aceptado: 4/2/2020

\begin{abstract}
Resumen
El presente trabajo tiene como objetivo analizar una serie de discursos en torno a la obra y a la figura de la artista Graciela Sacco, en relación con el desarrollo de prácticas artísticas feministas en la Ciudad Autónoma de Buenos Aires y siguiendo los estudios realizados por Andrea Giunta sobre el tema (1994-2018). A tal fin, se estudiarán diferentes casos en los que se ha tomado como ejemplo su obra o se la ha vinculado con prácticas artísticas feministas, y se incorporarán debates actuales -recuperados a través de notas y posteos en redes socialescomo parte importante en la construcción de nuevas miradas sobre la obra de esta artista.
\end{abstract}

\section{Palabras clave}

Feminismo(s); arte; Graciela Sacco; Andrea Giunta

\begin{abstract}
The objective of the present work is to analyze the series of speeches that revolve around the work and the figure of the artist Graciela Sacco, following the studies of Andrea Giunta about the subject (1994-2018) and in relation to the development of feminist art practices in the artistic circle of Buenos Aires. To achieve this end, different cases in which her work was taken as an example or was related to feminist art practices. In order to evidence the contribution of these views about her production, giving light to the conflicts of the present and incorporating the debates in social media as an important part for the construction of new views.
\end{abstract}

\section{Keywords}

Feminism(s); art; Graciela Sacco; Andrea Giunta 


\section{ARTICULOS}

«Celebridad, novedad, excepcionalidad, son los mitos construidos por una cultura dominada por la masculinidad para "acotar" el hecho de la continua participación de las mujeres en la producción artística.» Griselda Pollock (2001)

1 En 1968 un grupo de artistas de vanguardia provenientes de Buenos Aires y de Rosario llevaron a cabo una serie de acciones y de manifestaciones en contra de la dictadura de Juan Carlos Onganía (1966-1970), partiendo de la situación de precariedad que se estaba viviendo en la provincia de Tucumán. Las mismas, se percibieron como una ruptura con las instituciones artísticas y las formas preestablecidas de concebir el arte.
Graciela Sacco (1956-2017) fue una artista visual y profesora argentina que trabajó principalmente con fotografía, video e instalación en múltiples soportes y formatos, y se destacó por el desarrollo de la técnica de la heliografía - algo que le dio su marca personal- También fue pionera en investigar sobre Tucumán Arde. ${ }^{1}$ Su producción es conocida por hablar de migraciones, de exilios y de conflictos sociales, por el uso de imágenes de archivo $y$, sobre todo, por su fuerte compromiso con la sociedad. Sus obras, que tienen un presente continuo que se hace evidente en las fechas - desde el año en que las realiza hasta el último en el que se presentan de nuevo-, han sido reactualizadas y vinculadas con diferentes enunciados durante toda su trayectoria. Tras su fallecimiento en 2017 su figura se hizo presente en los debates por una práctica artística feminista, algo que generó respuestas negativas en ciertos ámbitos académicos que pretendían homenajearla. ¿Quéimplica la construcción de una práctica artística feminista en la Argentina?

\section{El cuerpo en primera persona}

Durante los años noventa, la problemática de género y sexualidad emerge en el campo artístico y tiene una repercusión mundial. En la Ciudad Autónoma de Buenos Aires comienza a cuestionarse el concepto de sujeto creativo, las temáticas, los procedimientos y materiales privilegiados, los criterios curatoriales y las modalidades narrativas de la Historia del Arte y la Crítica. En 1994 la historiadora y crítica de arte Andrea Giunta realiza su primer escrito desde una perspectiva de género tomando la obra de Sacco como objeto de estudio. Ese mismo año en Buenos Aires comienza la publicación de la revista Mora, revista del Área Interdisciplinaria de Estudios de la Mujer del Instituto Interdisciplinario de Estudios de Género, de la Facultad de Filosofía y Letras (FFyL) de la Universidad de Buenos Aires (UBA), en cuyo segundo número de 1996 se publica el ensayo sobre Sacco. 
2 Ya en la década del ochenta se habían realizado experiencias de exposición que tomaban como punto de partida el papel de la mujer, Mitominas 1 fue una muestra interdisciplinaria que se llevó a cabo entre el 7 y el 30 de noviembre de 1986 en el Centro Cultural Ciudad de Buenos Aires (CCCBA, actual Centro Cultural Recoleta). La propuesta de la exposición partió de la revisión, el cuestionamiento y la reinterpretación de la mirada acerca de papel de la mujer en mitos grecolatinos y americanos (Rosa, 2014).
En su escrito, la autora se dedica a analizar dos series de la artista, La Maja anunciada (1991-93) y Las Historias de Venus (1992-93), y señala diferentes aspectos de las obras que le permitieron vincularlas con una perspectiva de género: la tematización sobre el cuerpo, los títulos y las visualidades utilizadas, así como los recursos plásticos y compositivos. De esta manera, para Giunta (1996), Sacco recurre un conjunto de procedimientos que le permiten utilizar el cuerpo como un soporte y como un parámetro desde el cual se propone revisar diversas construcciones sociales del sentido, como la representación de lo femenino. Tal es el caso de las series de Venus en donde se deja explicitada una intencionalidad de reapropiación y relectura de la representación de la mujer, que se presenta como parte de un proceso de ruptura con la tradición: "Sacco reescribe, con sus impresiones luminosas, la construcción social y popular que Berni hace de la mujer. Se apropia de una imagen que confirma la intencionalidad polémica que subyace en su redefinición de lo femenino" (Giunta, 1996, p. 78). A pesar de ello, ese no era un momento en el que muchas artistas se identificaran como mujeres y feminismo era un término que carecía de legitimidad. Por el contrario, la palabra género resultaba más adecuada. Este hecho podría estar emparentado con la creciente fuerza que habían tomado las investigaciones realizadas por artistas pertenecientes al Centro Cultural Rojas. Al momento, no había contexto de enunciación legítimo para el feminismo en el campo del arte ya que «era visto, predominantemente, como un tema del pasado vinculado a una agenda anticuada y superada por las perspectivas de género que involucraban el problema de las sexualidades disidentes desde una comprensión más inclusiva» (Giunta, 2018, p. 61). Sin embargo, no puede dejarse de lado el vínculo con el contexto emergente que hay en la obra de Sacco y su intencionalidad como artista, que forma parte activa de un proceso que ya había estado presente en décadas anteriores ${ }^{2}$ pero que todavía no tenía visibilidad dentro de la crítica.

\section{Arte y feminismo}

Tras su fallecimiento en 2017 su figura cobró gran protagonismo en las redes sociales, ya que diferentes personalidades del escenario artístico realizaron publicaciones conmovidas por la noticia. Estas declaraciones, no solo estuvieron movilizadas por la tristeza, sino que también dieron lugar a un claro mensaje político. La figura de Sacco se hizo presente en la conformación 
de Nosotras Proponemos, un compromiso de práctica artística feminista que estaba gestándose desde hacía tiempo pero que fue impulsado por esa circunstancia para hacer su primera aparición en un posteo realizado por la artista Leticia Obeid. Este acontecimiento resulta clave en la participación y en el cambio de perspectivas tanto dentro como fuera de las instituciones del campo artístico, y contribuye a visibilizar las problemáticas que la artista rosarina, según estas declaraciones, tuvo que enfrentar. "Es fundamental reconocer que el feminismo no es un dogma ni una teoría homogénea, sino una forma de ver y analizar el mundo tomando en cuenta la primacía de las relaciones de género como relaciones de poder» (Pollock, 2001, p. 7). Siguiendo esta línea, podemos analizar la situación acontecida en la muestra homenaje Preguntas que tuvo lugar ese mismo año en el Museo de la Universidad Nacional de Tres de Febrero (MUNTREF).

\section{Homenaje}

Preguntas-Graciela Sacco tuvo lugar entre marzo y junio del 2018 en el MUNTREF, ubicado en la ex sede del Hotel de Inmigrantes. La muestra fue curada por Diana Wechsler y Fernando Farina y concentró gran cantidad del trabajo de la artista. No solo fue muy importante por reunir las obras más emblemáticas, sino por estar situada en un lugar significativo en su trayectoria como lo fue esta locación. Así como las obras dialogaban entre sí durante todo el recorrido, la muestra también estuvo acompañada por otro mensaje que, si bien no aparentaba ser central en la lectura general, no deja de presentar una importante carga simbólica en el contexto actual.

Uno de sus curadores realizó en su escrito un comentario particular en el que reprobaba la asimilación de Sacco a la lucha feminista: "Confieso que en ese momento temí que se la quisiera convertir en la adalid de la lucha feminista o ponerla al frente de cualquier otra causa que respondiera a un interés personal» (Farina en Wechsler y otros, 2018, s. p.). A este comentario se sumaron las palabras de Aníbal Y. Jozami, rector de la Universidad Nacional de Tres de Febrero (UNTREF), quien declaró en el prólogo de la muestra: "Graciela Sacco expresaba a través de sus creaciones artísticas la búsqueda de una vida mejor para todos, independientemente de los partidismos o de las ideologías» (Jozami en Wechsler y otros, 2018 , s. p.). 
Estas declaraciones, visibilizan la hegemonía de un discurso que coloca a Sacco y a sus obras en función de un mayor compromiso político y social, mientras manifiestan una clara deslegitimación de la perspectiva feminista que ha tomado fuerza en los últimos años. De esta forma, no sólo ocultan estudios realizados acerca del vínculo entre su obra y el feminismo, sino que también limitan la posibilidad de generar nuevos análisis - para lo que el irremediable silencio de Sacco resulta a su favor-.

\section{Reactualización/reflexión}

En los meses posteriores a la muestra homenaje una de las versiones de la serie Bocanada (1993-2014) fue elegida para formar parte de la muestra colectiva Siete mujeres a la conquista de la Luna, realizada como parte de las acciones por el mes de la mujer, \#8M, en el Museo Nacional de Bellas Artes, curada por Andrés Duprat y por Mariana Marchesi. Esta obra, reproducida por la artista en múltiples formatos, soportes y diferentes contextos sociales, estuvo siempre vinculada con la denuncia del hambre en el mundo. En contraste, en una reseña de la muestra, las bocanadas cobran un nuevo sentido y se convierten en arquetipos de lucha, ya que son interpretadas como "símbolo inequívoco de que las mujeres decidieron ser escuchadas por un lugar más justo en la historia del arte» (Costa Peuser, 2018, s. p.).

Esto pone en evidencia un cambio de enfoque desde el cual es posible analizar y reactualizar una obra como Bocanada desde el feminismo. Algo que también conlleva la tarea reflexiva de remitirnos al sentido político que implica el lugar desde el que están incluidas las artistas que participaron de la muestra, para evitar caer en generalizaciones e incluirlas meramente por el hecho de ser mujeres.

En América Latina las artistas han resistido la identificación de artistas feministas, incluso de artistas mujeres (Giunta, 2018). Desde una perspectiva histórica es importante dar cuenta de las diferencias, ya que en ellas se inscriben políticas específicas y subjetividades que no pueden uniformarse; que la obra sea producto de una artista mujer no significa que sea una obra feminista. Por lo tanto, lejos de hablar de Sacco como adalid de la lucha feminista o, por el contrario, de invisibilizar los cuestionamientos manifiestos en sus obras, resulta significativo evidenciar el vínculo que hay 
entre su trayectoria y el desarrollo de una teoría feminista del arte. Este análisis nos sirve de ejemplo para percibir la complejidad con la que se fue circunscribiendo la teoría feminista dentro del campo artístico en la Ciudad Autónoma de Buenos Aires, complejidad que al día de hoy continúa vigente. Asimismo, nos marca la importancia de poner atención a la toma de decisiones por parte de las instituciones, así como al rol que ocupan las exposiciones, al ser espacios fundamentales de debate en la construcción y en la visibilización de otros/nuevos discursos. Entonces nos preguntamos: ¿una bocanada en el feminismo se disputa?, ¿quiénes pueden disputarla?, ¿hay lugar para el debate?

\section{Referencias}

Pollock, G. (2001). Visión, voz y poder: historias feministas del arte y marxismo. En K. Cordero Reiman e I. Sáenz (Comps), Crítica feminista en la teoría e historia del arte (pp. 45-80). Ciudad de México, México: Universidad Iberoamericana, PUEG.

Costa Peuser, M. (7 de marzo de 2018). Siete mujeres a la conquista de la Luna. Iluminan el Bellas Artes. Arte Online. Recuperado de https://www.arte-online.net/Notas/Siete_mujeres_a_la_ conquista_de_la_Luna

Duprat, A. y Marchesi, M. (2018). A la conquista de la luna. Dowek - Bairon - Sacco - Porter - Millán - Gerstein - Forner [Exposición]. Ciudad Autónoma de Buenos Aires, Argentina: Museo Nacional de Bellas Artes. Recuperado de https://www.bellasartes.gob.ar/ exhibiciones/a-la-conquista-de-la-luna

Giunta, A. (1996). Territorios del cuerpo. Las heliografías de Graciela Sacco. Mora. Revista del área interdisciplinaria de estudios de la mujer, (2), 75-82.

Giunta, A. (2018). Feminismo y arte latinoamericano. Ciudad Autónoma de Buenos Aires, Argentina: Siglo Veintiuno.

Nosotras Proponemos. (s. f.). Home. Compromiso de práctica artística feminista. Asamblea permanente de trabajadoras del arte. Recuperado de http://nosotrasproponemos.org/ 
Rosa, M. L. (2014). Legados de Libertad. El arte feminista en la efervescencia democrática. Ciudad Autónoma de Buenos Aires, Argentina: Biblos.

Wechsler, D.; Jozami, Y. A. y Farina, F. (2018). Preguntas, Graciela Sacco [Catálogo de exposición]. Ciudad Autónoma de Buenos Aires, Argentina: Museo de la Universidad Nacional de Tres de Febrero. 